\title{
Macrophage endocytosis of high-mobility group box 1 triggers pyroptosis
}

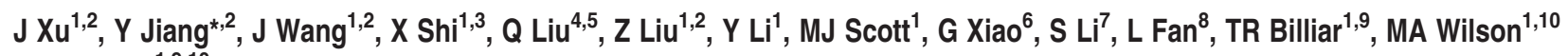 \\ and $\mathrm{J}$ Fan $^{\star, 1,9,10}$
}

Macrophages can be activated and regulated by high-mobility group box 1 (HMGB1), a highly conserved nuclear protein. Inflammatory functions of HMGB1 are mediated by binding to cell surface receptors, including the receptor for advanced glycation end products (RAGE), Toll-like receptor (TLR)2, TLR4, and TLR9. Pyroptosis is a caspase-1-dependent programmed cell death, which features rapid plasma membrane rupture, DNA fragmentation, and release of proinflammatory intracellular contents. Pyroptosis can be triggered by various stimuli, however, the mechanism underlying pyroptosis remains unclear. In this study, we identify a novel pathway of HMGB1-induced macrophage pyroptosis. We demonstrate that HMGB1, acting through RAGE and dynamin-dependent signaling, initiates HMGB1endocytosis, which in turn induces cell pyroptosis. The endocytosis of HMGB1 triggers a cascade of molecular events, including cathepsin B release from ruptured lysosomes followed by pyroptosome formation and caspase-1 activation. We further confirm that HMGB1-induced macrophage pyroptosis also occurs in vivo during endotoxemia, suggesting a pathophysiological significance for this form of pyroptosis in the development of inflammation. These findings shed light on the regulatory role of ligand-receptor internalization in directing cell fate, which may have an important role in the progress of inflammation following infection and injury.

Cell Death and Differentiation (2014) 21, 1229-1239; doi:10.1038/cdd.2014.40; published online 25 April 2014

Infection and injury, the most challenging factors to the survival of species throughout evolution, are still major causes of human death worldwide. Infection and severe trauma share many overlapping features in the mechanism of activation of the innate immune system through pathogen-associated molecular pattern molecules derived from microbes and damage-associated molecular pattern (DAMP) molecules released by damaged tissues. ${ }^{1,2}$ High-mobility group box 1 (HMGB1), a highly conserved ubiquitous protein present in the nucleus and cytoplasm of nearly all cell types, is the prototypic DAMP molecule. ${ }^{3}$ During infection and sterile tissue injury, HMGB1 is released from cells and serves as a necessary and sufficient mediator of inflammation to induce a variety of cellular responses including cell chemotaxis and release of pro-inflammatory cytokines. $^{4,5}$ Inflammatory functions of HMGB1 are mediated by binding to the cell surface receptors, including the receptor for advanced glycation end products (RAGEs), Toll-like receptor (TLR)2, TLR4, and TLR9., 6,

RAGE is a type I transmembrane protein and a member of the immunoglobulin superfamily expressed in many cell populations, including endothelial cells, vascular smooth muscle cells, neurons, neutrophils, and macrophages/monocytes. ${ }^{8}$ RAGE has been implicated as a receptor mediating the chemotaxis and cytokine activity of HMGB1 in macrophages and tumor cells. ${ }^{7,9,10}$ RAGE engagement by multiple ligands is linked to a range of signaling pathways including activation of NF-kB, ${ }^{11,12} \mathrm{PI}$ IK/Akt, ${ }^{13}$ MAPKs, ${ }^{14,15}$ Jak/STAT, ${ }^{16}$ and Rho GTPases, ${ }^{17}$ although how RAGE transduces the signaling is not fully addressed.

Pyroptosis is a caspase-1-dependent programmed cell death, which is morphologically and mechanistically distinct from other forms of cell death such as apoptosis and necrosis. ${ }^{18}$ Previous observations suggested that pyroptosis features rapid plasma membrane rupture and release of proinflammatory intracellular contents, contrasting with the characteristic of apoptosis, which packs cellular contents and induces non-inflammatory phagocytic uptake of the apoptotic bodies by macrophages. ${ }^{19}$ Pyroptosis can be triggered by various pathological stimuli, such as microbial infection, stroke, heart attack, or cancer; ${ }^{18}$ however, the mechanism that underlies pyroptosis formation in response to inflammatory mediators remains unclear. In this study, we identify a

\footnotetext{
${ }^{1}$ Department of Surgery, University of Pittsburgh School of Medicine, Pittsburgh, PA, USA; ${ }^{2}$ Department of Pathophysiology, Southern Medical University, Guangzhou, China; ${ }^{3}$ Department of Pharmacology, Medical College of Xi'an Jiaotong University, Xi'an, China; ${ }^{4}$ Department of Surgery, Thomas E. Starzl Transplantation Institute, University of Pittsburgh School of Medicine, Pittsburgh, PA, USA; ${ }^{5}$ Department of Cardiovascular Surgery, Second Affiliated Hospital of Harbin Medical University, Harbin, China; ${ }^{6}$ Department of Biochemistry, Rush University Medical Center, Chicago, IL, USA; ${ }^{7}$ Center for Pharmacogenetics, Department of Pharmaceutical Sciences, University of Pittsburgh School of Pharmacy, Pittsburgh, PA, USA; ${ }^{8}$ University of Pittsburgh School of Arts and Science, Pittsburgh, PA, USA; ${ }^{9}$ McGowan Institute for Regenerative Medicine, University of Pittsburgh, Pittsburgh, PA, USA and ${ }^{10}$ Research and Development, Veterans Affairs Pittsburgh Healthcare System, Pittsburgh, PA, USA

${ }^{*}$ Corresponding author: Y Jiang, Department of Pathophysiology, Southern Medical University, Guangzhou 510515, China. Tel: +86 02061648231 ; Fax:+86 02061648233 ; E-mail: jiang48231@163.com

or J Fan, Department of Surgery, University of Pittsburgh School of Medicine, Building 1, 2W109 (151U-L) University Drive, VAPHS, Pittsburgh, PA 15261, USA. Tel: +1 412360 6204; Fax: +1 412360 6633; E-mail: jif7@ pitt.edu

Abbreviations: HMGB1, high-mobility group box 1; RAGE, receptor for advanced glycation end product; TLR, Toll-like receptor; CatB, cathepsin B; DAMPs, damageassociated molecular pattern; BMM, bone marrow-derived macrophages; AMs, alveolar macrophages; CT-B, cholera toxin-B; ASC, apoptosis-associated speck-like protein containing a CARD

Received 11.8.13; revised 22.2.14; accepted 05.3.14; Edited by RA Knight; published online 25.4.14
} 
novel pathway of HMGB1-induced pyroptosis. We demonstrate that HMGB1 acting through RAGE on macrophages triggers dynamin-dependent endocytosis of HMGB1, which in turn induces cell pyroptosis. The endocytosis of HMGB1 initiates a cascade of molecular events, including cathepsin B (CatB) activation and release from ruptured lysosomes, followed by pyroptosome formation and caspase-1 activation. We further confirm that this in vitro observation of HMGB1-induced macrophage pyroptosis also occurs in vivo during endotoxemia, suggesting a pathophysiological significance for pyroptosis in the development of inflammation.

\section{Results}

Macrophage endocytosis of HMGB1 is a RAGE-mediated event. HMGB1 as an endogenous DAMP molecule is critically involved in the development of inflammation both at sites of infection and at sterile tissue injury. The precise mechanism of HMGB1 regulation of cellular immune responses remains unclear. In our study defining how HMGB1 signals to produce macrophage responses, we observed rapid endocytosis of HMGB1 in macrophages. As shown in Figure 1a, treatment of mouse alveolar macrophages (AMs) with HMGB1-enhanced green fluorescent protein (EGFP; $100 \mathrm{nmol} / \mathrm{l}$ ) induced HMGB1-EGFP internalization that occurred in as soon as $5 \mathrm{~min}$ after the treatment. This HMGB1-EGFP internalization was specific phagocytosis via HMGB1 in the AMs as EGFP alone was not internalized. The dose-response results are shown in Figure 1b. An apparent HMGB1-EGFP endocytosis can be seen at a concentration of $50 \mathrm{nmol} / \mathrm{l}$. To further define whether HMGB1-EGFP internalization is a specific receptordependent event, we isolated bone marrow-derived macrophages (BMMs) from TLR2 ${ }^{-1-}$, $\mathrm{TLR}^{-/-}$, and $\mathrm{RAGE}^{-1-}$

a HMGB1-EGFP (100 nmol/L)
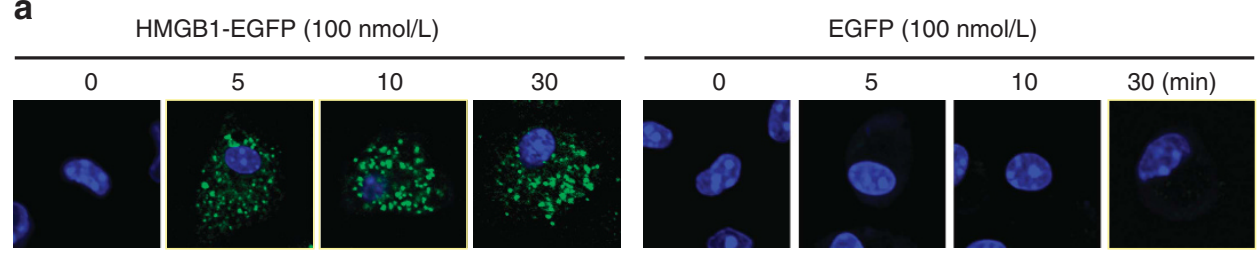

b

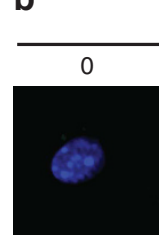

HMGB1-EGFP (30 min)

C

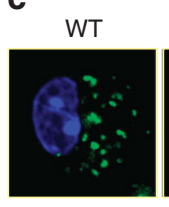

$\mathrm{TLR}^{-1-}$

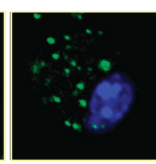

e

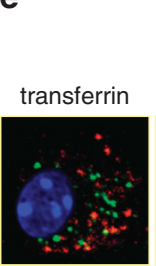

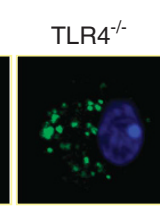
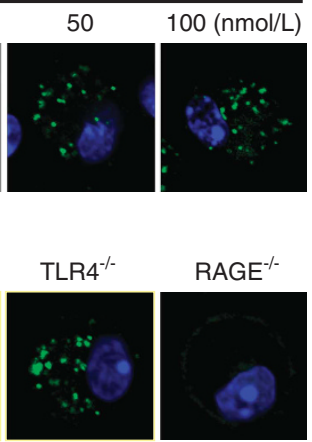

f d
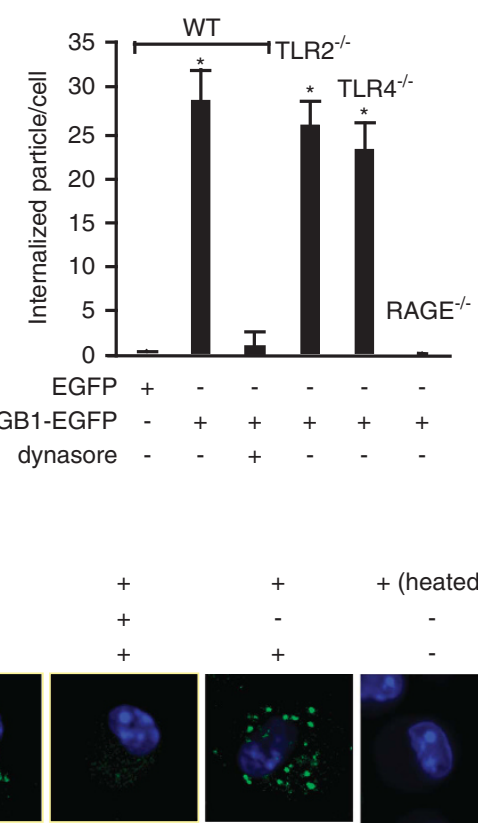

+ (heated)

$-$

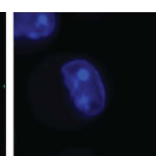

Figure 1 Macrophage endocytosis of HMGB1 is mediated by RAGE-dependent pathway. (a) Confocal microscopy of alveolar macrophages (AMs) that were isolated from C57BL/6 (wild type, WT) mice and incubated with recombinant protein HMGB1-EGFP (100 nmol/l) or EGFP for 0-30 min. Original magnification $\times 600$; results are representative of three independent experiments. (b) Confocal microscopy of AMs that were isolated from WT mice and incubated with 0-100 nmol// HMGB1-EGFP for 30 min. Original magnification $\times 600$; results are representative of three independent experiments. (c) Confocal microscopy of AMs that were isolated from WT, TLR2 ${ }^{-1-}$, $\mathrm{TLR}^{-1-}$, or RAGE ${ }^{-1-}$ mice and incubated with HMGB1-EGFP $(100 \mathrm{nmol} / \mathrm{l})$ for $30 \mathrm{~min}$. Original magnification $\times 600$; results are representative of three independent experiments. (d) Changes in average number of intracellular EGFP-tagged protein particles in AMs, which were calculated using confocal microscopy program. The AMs were isolated from WT, TLR2 ${ }^{-1-}$, TLR4 ${ }^{-1-}$, or RAGE ${ }^{-1-}$ mice and incubated with HMGB1-EGFP $(100 \mathrm{nmol} /$ ) for 30 min. In some experiments, WT AMs were incubated with HMGB1-EGFP and dynamin inhibitor dynasore $(30 \mu \mathrm{g} / \mathrm{ml})$ for $30 \mathrm{~min}$. The graph shows the mean and S.D., $n=9 .{ }^{*} P<0.05$ versus the group treated with EGFP alone. (e) Confocal microscopy of AMs that were isolated from WT mice and incubated with HMGB1-EGFP and Alexa fluor 568-labeled transferrin, a protein that is typically endocytosed through clathrin-dependent pathways, or Alexa fluor 568-labeled cholera toxin (CT)-B, a tracker of lipid raft-dependent pathways. Original magnification $\times 600$; results are representative of three independent experiments. (f) Confocal microscopy of WT AMs that were incubated with HMGB1-EGFP in the presence or absence of dynasore $(30 \mu \mathrm{g} / \mathrm{ml})$ or DMSO $(0.3 \%)$ for $30 \mathrm{~min}$. WT AMs were also treated with heated HMGB1-EGFP $\left(100^{\circ} \mathrm{C}, 5 \mathrm{~min}\right)$ for 30 min. Original magnification $\times 600$; results are representative of three independent experiments 
mice and then treated the cells with HMGB1-EGFP $(100 \mathrm{nmol} / \mathrm{l})$. The results showed that RAGE deficiency prevented HMGB1 internalization, whereas genetic deletion of TLR2 or TLR4 failed to block HMGB1 internalization (Figures 1c and d), indicating that HMGB1 internalization is RAGE depends. To further determine the pathway of HMGB1 internalization, we treated BMMs with HMGB1EGFP and Alexa fluor 568-labeled transferrin, a protein that is typically endocytosed through clathrin-dependent pathways, or Alexa fluor 568-labeled cholera toxin (CT)-B, a tracker of lipid raft-dependent pathways. As demonstrated in Figure 1e, internalized HMGB1 did not co-localize with transferrin and CT-B, suggesting that HMGB1 internalization is not mediated through clathrin- or lipid raft-dependent pathways. In contrast, we observed that treatment of the cells with dynamin inhibitor dynasore $(30 \mu \mathrm{g} / \mathrm{ml}$ in $0.3 \%$ DMSO, Sigma-Aldrich, St. Louis, MO, USA) effectively blocked HMGB1 internalization as shown in Figures 1d and $\mathrm{f}$. The dynasore solvent DMSO alone did not suppress HMGB1 endocytosis (Figure 1f). In order to address if the HMGB1 endocytosis is possibly mediated by contaminated lipopolysaccharide (LPS), HMGB1-EGFP was heated at $100^{\circ} \mathrm{C}$ for $5 \mathrm{~min}$ before adding to the BMMs. As shown in Figure 1f, heated HMGB1-EGFP failed to induce its endocytosis. Taken together, HMGB1 acting through RAGE initiates its endocytosis into macrophages via a dynamindependent pathway.

Localization of HMGB1 in Iysosomes induces lysosomal destabilization and CatB activation. To track the translocation of endocytosed HMGB1-EGFP in the macrophages, we visualized endosomes and lysosomes with Alexa Fluor 555-tagged anti-early endosome antigen antibody, an endosome detector and LysoTracker probe (Molecular Probes, Eugene, OR, USA), a lysosome detector. We observed that HMGB1 localized in endosomes starting at $15 \mathrm{~min}$ after HMGB1 treatment (Figure 2a), followed by translocation into lysosomes at $3 \mathrm{~h}$, and it remained there for at least $9 \mathrm{~h}$ (Figure 2b). We then applied fluorescencetagged $\mathrm{DQ}$ ovalbumin to monitor the integrity of the endo-lysosome compartments in the macrophages after HMGB1 endocytosis. The fluorescence of the fluorophore BODIPY-FL (8-chloromethyl-4,4-difluoro-1,3,5,7-tetramethyl4-bora-3a,4a-diaza-s-indacene) on DQ ovalbumin is normally quenched unless the protein is proteolytically processed into peptides in endo-lysosomal compartments. ${ }^{20}$ As shown in Figure $2 \mathrm{c}$, in untreated cells (time $=0 \mathrm{~h}$ ), processed DQ ovalbumin was localized to small vesicular and tubular endosomes or lysosomes, as expected. However, notably, there were large swollen lysosomes in more than $85 \%$ of macrophages starting from $6 \mathrm{~h}$ after HMGB1 treatment. The cells demonstrated a cytosolic pattern of fluorescently processed DQ ovalbumin, which suggested lysosomal rupture or leakage of lysosomal contents into the cytosol ${ }^{21,22}$ of HMGB1-treated macrophages (Figure 2c).

Lysosomes contain a plethora of proteolytic enzymes including the cathepsin family. ${ }^{23}$ Activation and release of CatB from lysosomes have been reported as an important mechanism of NLRP3 inflammasome activation following silica crystal uptake. ${ }^{20}$ To address whether the observed lysosome rupture leads to CatB activation, we measured CatB activity in the cytosol using Magic Red CatB detection reagent. In wild-type (WT) macrophages, a cytosolic pattern of activated CatB staining was observed at $12 \mathrm{~h}$ after HMGB1 treatment (Figure 2d). The densitometry analysis showed that cytosolic CatB activity started to increase at $9 \mathrm{~h}$ after HMGB1 treatment and reached a 3.5 -fold increase at $12 \mathrm{~h}$, as shown in Figure 2e. In contrast, HMGB1 failed to induce CatB activation in RAGE knockout macrophages (Figures 2d and f) as well as WT macrophages pretreated with dynasore (Figure $2 \mathrm{~g}$ ). No effect from dynasore solvent DMSO was found in the experiments as shown in Figures $2 \mathrm{~d}$ and $\mathrm{g}$. Collectively, these results show that endocytosis of HMGB1 leads to active swelling of lysosomes followed by lysosome destabilization and rupture, therefore resulting in the activation and release of CatB into the cytosolic compartment.

HMGB1 endocytosis results in NIrp3 inflammasomeindependent caspase-1 activation. To determine whether CatB activation and release into the cytosol leads to caspase-1 activation, we investigated caspase-1 cleavage in the BMMs that were treated with HMGB1 for up to $12 \mathrm{~h}$. Caspase-1 cleavage was apparent between 3 and $12 \mathrm{~h}$ after HMGB1 treatment (Figure 3a). Noteworthy, HMGB1-induced caspase-1 cleavage at $12 \mathrm{~h}$ after HMGB1 treatment was prevented by dynamin inhibition (Figure 3b) or RAGE deletion (Figure 3c), both of which block HMGB1 endocytosis. Furthermore, inhibition of CatB activation, a downstream event after HMGB1 endocytosis, by pre-treating WT BMMs with CatB inhibitor CA074me (Sigma-Aldrich) markedly prevented HMGB1-induced caspase-1 cleavage at $12 \mathrm{~h}$ as shown in Figure 3b. The data indicate that HMGB1 acting through separate pathways induces early $(3 \mathrm{~h})$ and late $(12 \mathrm{~h})$ caspase-1 activation, respectively, and HMGB1 endocytosis is responsible for the late-phase activation of caspase- 1.

Nirp3 inflammasomes have been reported as major machinery involved in caspase-1 activation in macrophages. ${ }^{24,25}$ To determine the role of NIrp3 inflammasome in HMGB1induced caspase-1 activation, we isolated BMMs from $\mathrm{Nlrp}^{-/-}$mice and treated the cells with HMGB1 for 3 and $12 \mathrm{~h}$. The genetic deletion of Nlrp3 prevented HMGB1induced caspase- 1 cleavage at the early phase $(3 \mathrm{~h})$ but had no effect on the caspase- 1 cleavage at the late phase $(12 \mathrm{~h}$; Figure 3d). Furthermore, NIrp3 deficiency also prevented LPS + ATP-induced caspase- 1 cleavage at $3 \mathrm{~h}$ (Figure $3 \mathrm{e}$ ), as expected. In aggregate, these results indicate that NIrp3 inflammasome is required for the HMGB1-induced earlyphase activation of caspase-1, whereas HMGB1 endocytosis and subsequent CatB activation account for late-phase activation of caspase-1.

HMGB1 endocytosis induces pyroptosome formation. We next investigated more deeply the mechanism of the late-phase activation of caspase-1. It has been reported that the pyroptosome, a complex including adaptor protein apoptosis-associated speck-like protein containing a CARD (ASC), also known as ASC focus, recruits pro-caspase-1, resulting in its activation and proteolysis to the mature form via neighboring activated caspase- 1 proteins. ${ }^{26}$ To determine whether the pyroptosome serves as machinery for 
a

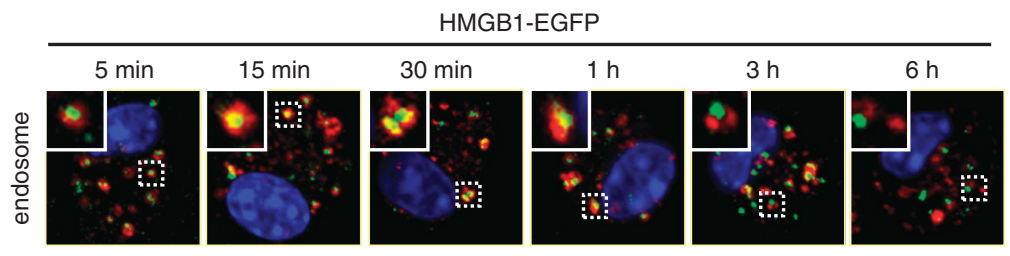

b HMGB1-EGFP

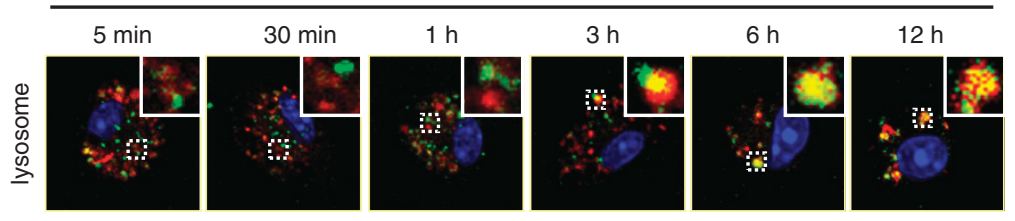

C HMGB1

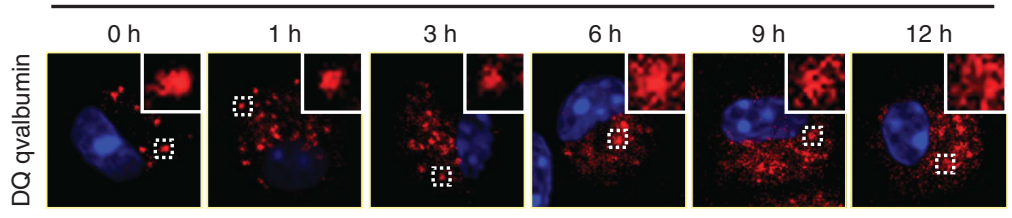

d
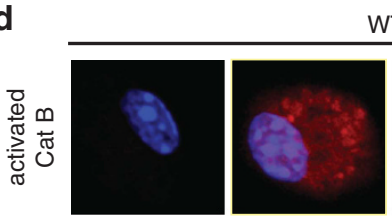

WT

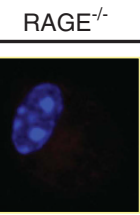

HMGB1

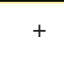

DMSO
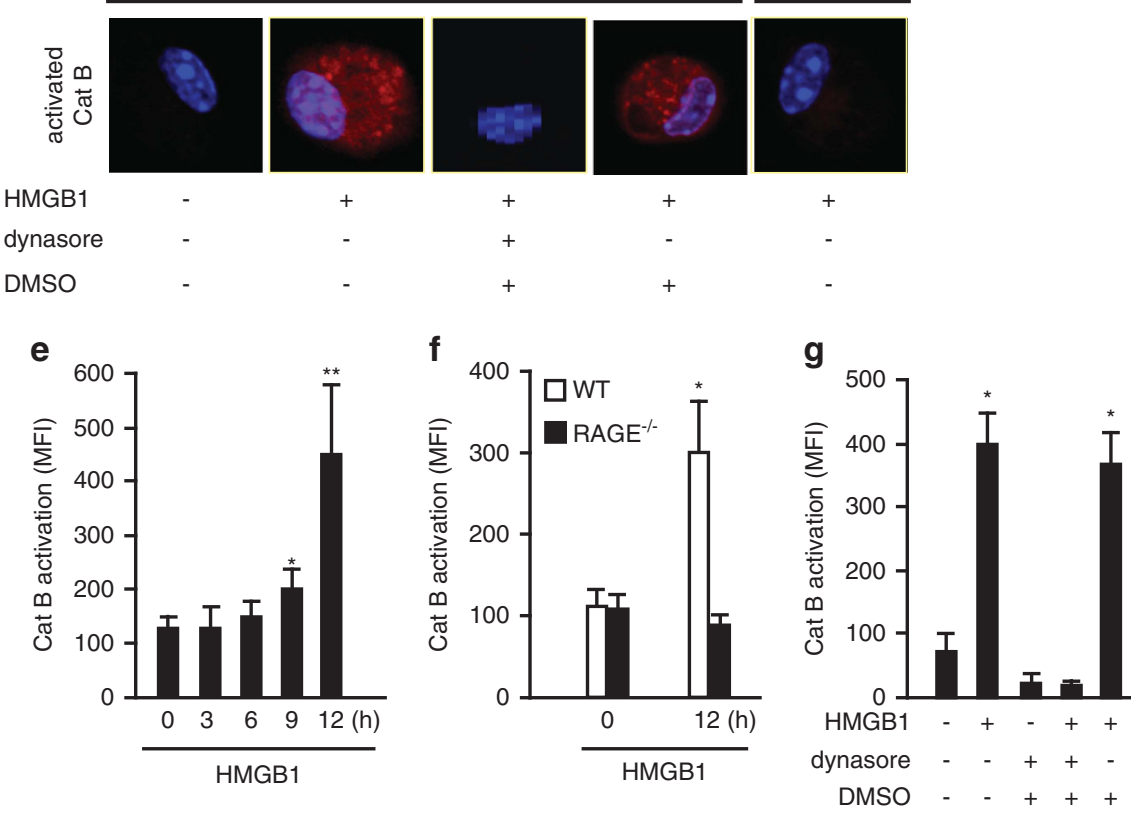

Figure 2 Localization of HMGB1 in lysosome induces lysosomal destabilization and cathepsin B (CatB) activation. (a) WT AMs were treated with HMGB1-EGFP (green, $100 \mathrm{nmol} / /)$ for $5 \mathrm{~min}, 15 \mathrm{~min}, 30 \mathrm{~min}, 1 \mathrm{~h}, 3 \mathrm{~h}$, or $6 \mathrm{~h}$, then immunofluorescence of early endosome antigen 1 (red) were detected. Original magnification $\times 600$; results are representative of three independent experiments. (b) AMs were incubated with both HMGB1-EGFP (green, $100 \mathrm{nmol} / \mathrm{l}$ ) and LysoTracker Red lysosome dye (red) for 5 min, $30 \mathrm{~min}, 1 \mathrm{~h}, 3 \mathrm{~h}, 6 \mathrm{~h}$, or $12 \mathrm{~h}$. Co-localization of HMGB1 and lysosome was detected using confocal microscopy. Original magnification $\times 600$; results are representative of three independent experiments. (c) AMs were treated with HMGB1 (50 nmol/l) for $0-12 \mathrm{~h}$ followed by incubation with DQ ovalbumin (red) for $1 \mathrm{~h}$ to visualize lysosome integrity using confocal microscopy. Original magnification $\times 600$; results are representative of three independent experiments. (d) AMs isolated from C57BL/6 (WT) or RAGE ${ }^{-}$ mice were incubated with HMGB1 (50 nmol/l) for $30 \mathrm{~min}$ in the absence or presence of dynasore $(30 \mu \mathrm{g} / \mathrm{ml})$ or DMSO $(0.3 \%)$. The cells were then stained with Magic Red CatB detection reagent (red) to visualize activated CatB under confocal microscopy. Original magnification $\times 600$; results are representative of three independent experiments. The insets show higher magnification views. (e-g) Macrophages were stained by Magic Red CatB detection reagent to detect the activation of CatB. The mean fluorescence intensity (MFI) of activated CatB was detected and analyzed using confocal microscopy and OLYMPUS Fluoview Ver.1.7c system. (e) WT AMs were stimulated with HMGB1 $(50 \mathrm{nmol} / /)$ for $0-12 \mathrm{~h}$ (mean and S.D., $n=5 .{ }^{*} P<0.05$ versus the group of $0 \mathrm{~h} ;{ }^{* *} P<0.01$ versus the group of $0 \mathrm{~h}$ ). (f) AMs isolated from WT or RAGE ${ }^{-l-}$ mice were stimulated with HMGB1 ( $50 \mathrm{nmol} / /)$ for $12 \mathrm{~h}$ (mean and S.D., $n=9 .{ }^{*} P<0.05$ versus the other groups). (g) WT AMs were stimulated with HMGB1 (50 $\left.\mathrm{nmol} / \mathrm{l}\right)$ for $12 \mathrm{~h}$ in the absence or presence of dynasore or DMSO (mean and S.D., $n=9 .{ }^{*} P<0.05$ versus the group labeled with no asterisk) 


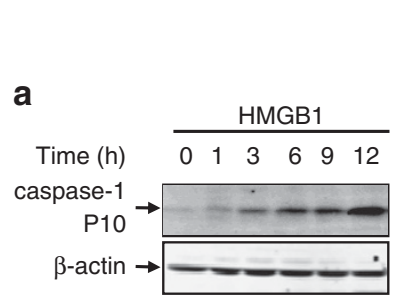

d b

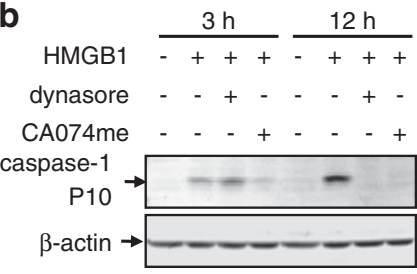

C

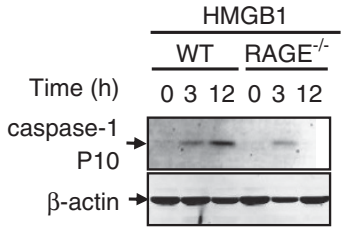

e

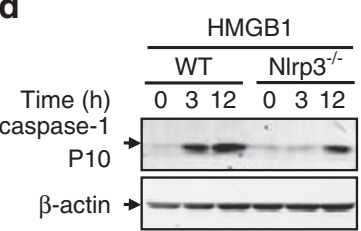

\begin{tabular}{|c|c|c|c|c|c|}
\hline \multirow[b]{2}{*}{ HMGB1(3h) } & \multicolumn{3}{|c|}{ WT } & \multicolumn{2}{|c|}{ NIrp3 ${ }^{-/-}$} \\
\hline & -+ & $+\quad-$ & - & -+ & $-\quad-$ \\
\hline LPS (3h) & -- & $-\quad+$ & + & $-\quad-$ & ++ \\
\hline $\operatorname{ATP}(1 \mathrm{~h})$ & - & $-\quad-$ & + & $-\quad-$ & $-\quad+$ \\
\hline $\begin{array}{r}\text { caspase-1 } \\
\text { P10 }\end{array} \rightarrow$ & & & & & \\
\hline$\beta$-actin & & & & & \\
\hline
\end{tabular}

Figure 3 CatB activation results in NIrp3-independent caspase-1 activation. (a-e) Immunoblot analysis of activation of caspase-1 in cell lysate of mouse BMMs. (a) WT BMMs were stimulated with HMGB1 (50 nmol/l) for 0-12 h. (b) WT BMMs were stimulated with HMGB1 in the presence or absence of dynasore or CA-074-me (10 $\mu \mathrm{mol} / \mathrm{l})$ for 3 and $12 \mathrm{~h}$, respectively. (c and d) BMMs isolated from WT, NIrp3 ${ }^{-1-}$, or RAGE ${ }^{-1-}$ mice were stimulated with HMGB1 for 3 or $12 \mathrm{~h}$, respectively. (e) BMMs isolated from WT mice or NIrp3 $3^{-1-}$ mice were either stimulated with HMGB1 for $3 \mathrm{~h}$ or challenged with LPS for $3 \mathrm{~h}$ followed by incubation with ATP for $1 \mathrm{~h}$. Images are representative of three independent experiments

HMGB1-induced late -phase caspase-1 activation, we visualized the ASC focus with florescence-tagged ASC antibody and confocal microscopy. At between 9 and $12 \mathrm{~h}$ after HMGB1 treatment, ASC foci were observed in WT BMMs (Figure 4a), but not in $\mathrm{RAGE}^{-/-}$BMMs or WT BMMs pre-treated with CatB inhibitor CA074me (Figures 4b and c).

As NIrp3 is dispensable in the late-phase activation of caspase-1 as shown in Figures $3 d$ and e, we next wanted to determine whether the pyroptosome, but not NIrp3 inflammasome, accounts for the caspase-1 activation. We measured the physical interaction of ASC and NIrp3 in BMMs in response to $12 \mathrm{~h}$ of treatment with HMGB1 or LPS plus ATP, a stimulation known to induce NIrp3 inflammasome activation. As demonstrated in Figure 4d, LPS + ATP induced a co-localization of ASC and NIrp3, suggesting an association of ASC and NIrp3 in NIrp3 inflammasome assembly. However, HMGB1-induced ASC foci were separate from NIrp3, and Nirp3 deletion failed to prevent the formation of ASC foci in response to HMGB1. There was no significant difference in the number of ASC foci between the cells of WT and NIrp3 ${ }^{-1-}$. These findings suggest that ASC has different roles in the pathways initiated by HMGB1 endocytosis and LPS + ATP.

To address ASC dependency of caspase-1 cleavage, we further knocked down ASC in J772.4 mouse macrophages using siRNA techniques. Knockdown of ASC in the cells significantly decreased HMGB1-induced caspase-1 cleavage at both 3 and $12 \mathrm{~h}$ (Figure $4 \mathrm{e}$ ). Considered together with the results shown in Figure $3 d$, the effect of ASC on caspase-1 cleavage at $12 \mathrm{~h}$ is an NIrp3 inflammasome-independent event.

HMGB1 endocytosis induces macrophage pyroptosis. Pyroptosis is a caspase-1-dependent programmed cell death. ${ }^{18}$ To determine whether pyroptosome formation and caspase-1 activation are followed by macrophage pyroptosis, we extended the observation time after the treatment of BMMs with HMGB1. At $18 \mathrm{~h}$ after HMGB1 stimulation, DNA fragmentation and caspase-1 activation, as detected by flow cytometry, occurred in the BMMs (Figure 5a), and morphologically, nuclear condensation (Figures $5 c$ and d) and enlarged cell size plus caspase- 1 activation (Figure $5 \mathrm{~d}$ ) were also observed using confocal microscopy. These cellular alterations are known characteristics of pyroptosis. ${ }^{27}$

To confirm the caspase-1 dependency of the observed pyroptosis, BMMs were treated with caspase-1 inhibitor Z-YVAD FMK 30 min before HMGB1 treatment. As shown in Figure 5a, caspase-1 inhibitor significantly suppressed HMGB1-induced cell death. This finding was further confirmed in the BMMs isolated from caspase-1 knockout mice and treated with HMGB1 (Figure 5b). Furthermore, suppression of CatB with its inhibitor CA074me prevented HMGB1-induced pyroptosis in the BMMs as well (Figure 5a). However, genetic deletion of NIrp3 did not prevent BMM pyroptosis at $18 \mathrm{~h}$ after HMGB1 treatment in a significant way (Figures $5 b$ and c). To further address if caspase-11, which may be inactive in caspase-1 genetic-deficient mice, is involved in the cell death mechanism, we knocked down caspase-11 in J772.4 mouse macrophages using siRNA techniques (Figure 5e). Knockdown of caspase-11 in the cells did not show an effect on the HMGB1-induced pyroptosis at $18 \mathrm{~h}$ (Figure 5f), although HMGB1 is able to induce caspase-11 activation (Figure 5e). In order to exclude a possible role of contaminated LPS in inducing the cell death, recombinant HMGB1 was heated at $100^{\circ} \mathrm{C}$ for $5 \mathrm{~min}$ before adding to the BMMs. The heated HMGB1 failed to induce the cell death. Considered together, the HMGB1-induced macrophage pyroptosis is an NIrp3 inflammasome-independent event.

To address whether the in vitro observation of HMGB1RAGE signaling-mediated induction of macrophage pyroptosis also occurs in vivo, we detected the number of pyroptotic macrophage/monocytes in the lungs and peripheral blood of endotoxemia mice. High circulating HMGB1 level in endotoxemia mice has been reported previously. ${ }^{3}$ Endotoxemia induced AMs pyroptosis (Figure 6a) and blood monocytes pyroptosis (Figure $6 \mathrm{~b}$ ) at $18 \mathrm{~h}$ after LPS injection in WT mice. However, injection of neutralizing antibody against HMGB1 $30 \mathrm{~min}$ before LPS markedly decreased monocyte pyroptosis in the blood following endotoxemia (Figure 6b). In contrast, 
a

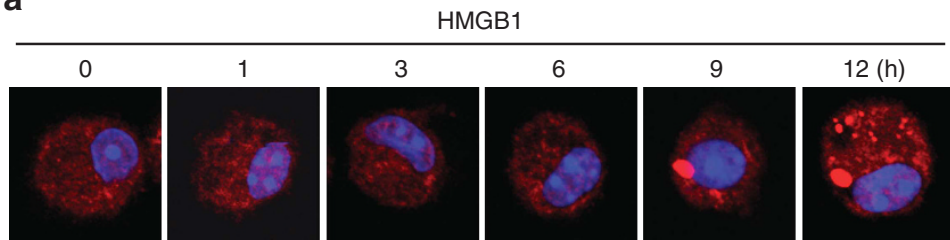

b

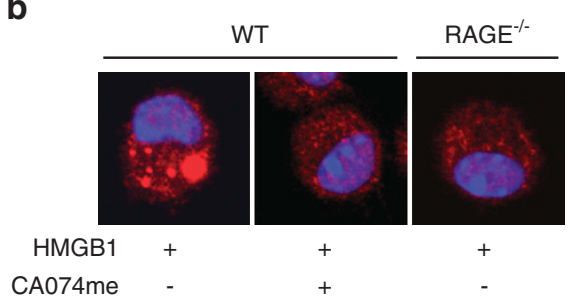

d

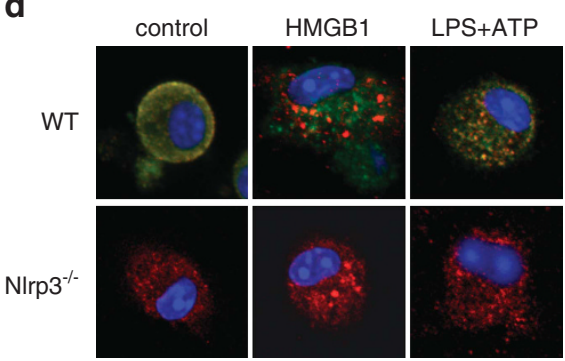

c

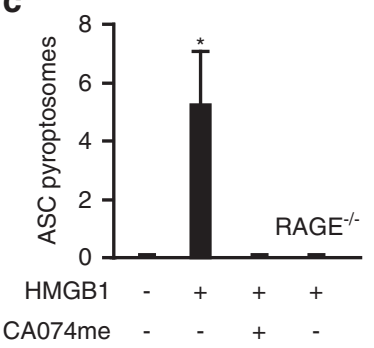

e

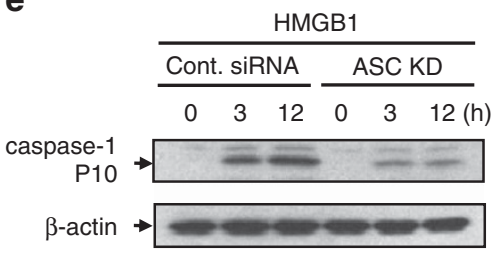

Figure 4 HMGB1-induced CatB activation and caspase-1 activation result in pyroptosome formation. (a and $\mathbf{b})$ Confocal microscopy results of immunofluorescence of ASC foci in BMMs (original magnification $\times 600)$. WT BMMs were treated with HMGB1 $(50 \mathrm{nmo} / /)$ for $0-12 \mathrm{~h}$, and ASC foci were stained to visualize pyroptosome formation (a). BMMs isolated from WT mice or RAGE ${ }^{-1-}$ mice were stimulated with HMGB1 $(50 \mathrm{nmol} / /)$ for $12 \mathrm{~h}$ in the presence or absence of CA-074-me $(10 \mu \mathrm{mol} / \mathrm{l})(\mathrm{b})$. (c) Alterations in average number of ASC focus in BMMs, which were calculated using OLYMPUS Fluoview Ver.1.7c system. BMMs isolated from WT mice or RAGE ${ }^{-1-}$ mice were stimulated with HMGB1 for $12 \mathrm{~h}$ in the presence or absence of CA-074-me followed by detection of ASC foci with florescence-tagged ASC antibody and confocal microscopy. The graph shows the mean and S.D., $n=9$. ${ }^{*} P<0.05$ versus all other groups. (d) BMMs isolated from WT mice or Nirp3 ${ }^{-1-}$ mice were treated with HMGB1 $(50 \mathrm{nmol} / \mathrm{l})$ for $12 \mathrm{~h}$ or sequentially treated with LPS $(3 \mathrm{~h})$ plus ATP $(1 \mathrm{~h})$, and ASC (red) and Nlrp3 (green) were detected by immunofluorescence and confocal microscopy (original magnification $\times 600$ ). (e) Mouse macrophage J774.2 cells were transfected with non-specific siRNA (Cont. siRNA) or ASC siRNA and stimulated with HMGB1 $(50 \mathrm{nmol} / \mathrm{l})$ for 0 or $12 \mathrm{~h}$. Caspase- 1 cleavage $(10 \mathrm{kDa})$ in the cell lysates was detected by immunoblotting analysis. Images are representative of three independent experiments

endotoxemia failed to increase blood pyroptotic monocytes in $\mathrm{RAGE}^{-1-}$ mice (Figure 6b). Taken together, the results suggest an in vivo role of the HMGB1-RAGE signaling in inducing macrophage/monocyte pyroptosis in endotoxemia.

\section{Discussion}

HMGB1 has a critical role at the intersection of the host inflammatory responses to both infectious and sterile threats. HMGB1 has been implicated as an endogenous proinflammatory mediator for inducing release of $\mathrm{TNF} \alpha, \mathrm{IL}-1 \beta$, and other proinflammatory cytokines, as well as mediating fever, anorexia, and the sickness syndrome in vivo. ${ }^{5}$ HMGB1 elicits cellular and biological inflammatory responses by signal transduction through several receptors that have been identified for their capacity to transduce activation signals from exogenous (TLR2, TLR4, and TLR9) and endogenous (RAGE) ligands. ${ }^{5}$ Previous studies established molecular mechanisms of HMGB1 binding and signaling through a TLR4-MyD88-NF- $\kappa$ B pathway that induces cytokine release and inflammation. ${ }^{5}$ However, the biological significance of the diversity of receptor signaling pathways initiated by
HMGB1has not yet been fully elucidated. In the current study, we identified a novel RAGE-dependent signaling pathway, by which HMGB1 induces cell pyroptosis. We demonstrated that HMGB1 acting through RAGE on macrophages triggers dynamin-dependent endocytosis of HMGB1, which in turn initiates a cascade of cellular and molecular events, including CatB activation and release from ruptured lysosomes. This rupture is followed by pyroptosome formation and caspase-1 activation, which serves as a mechanism underlying the HMGB1-induced pyroptosis (Figure 7). These findings suggest a distinct HMGB1-initiated pathway that differs from those previously reported.

Endocytosis has important roles in many different areas of cell biology, ranging from the uptake of nutrients to regulation of intercellular signaling. ${ }^{28}$ Endocytic pathways have been mainly classified as clathrin-dependent or -independent, ${ }^{28}$ the later can be further classified as dynamin-dependent or independent pathway. Dynamin is a large GTPase directly involved in pinching off endocytic vesicles from the plasma membrane. ${ }^{29-31}$ The dynamin activation in this study is secondary to RAGE activation, as genetic deletion of RAGE prevented HMGB1 endocytosis. Although RAGE was the first 
a

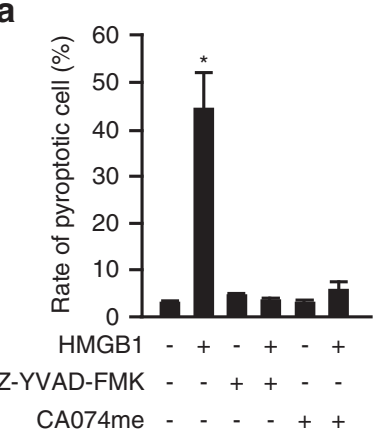

b

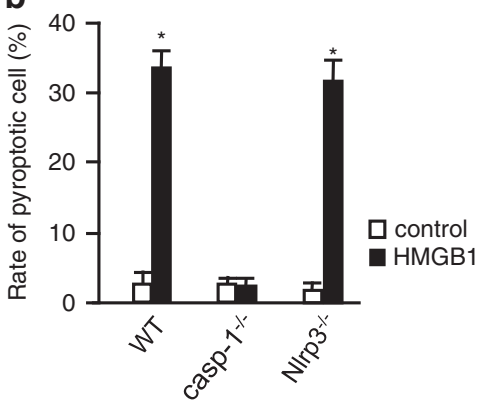

C
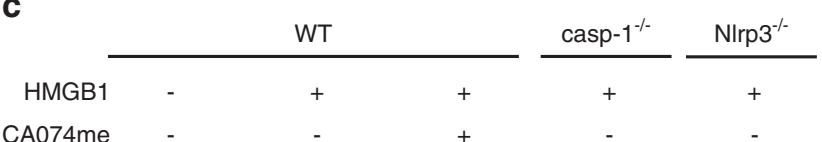

d

CA074me
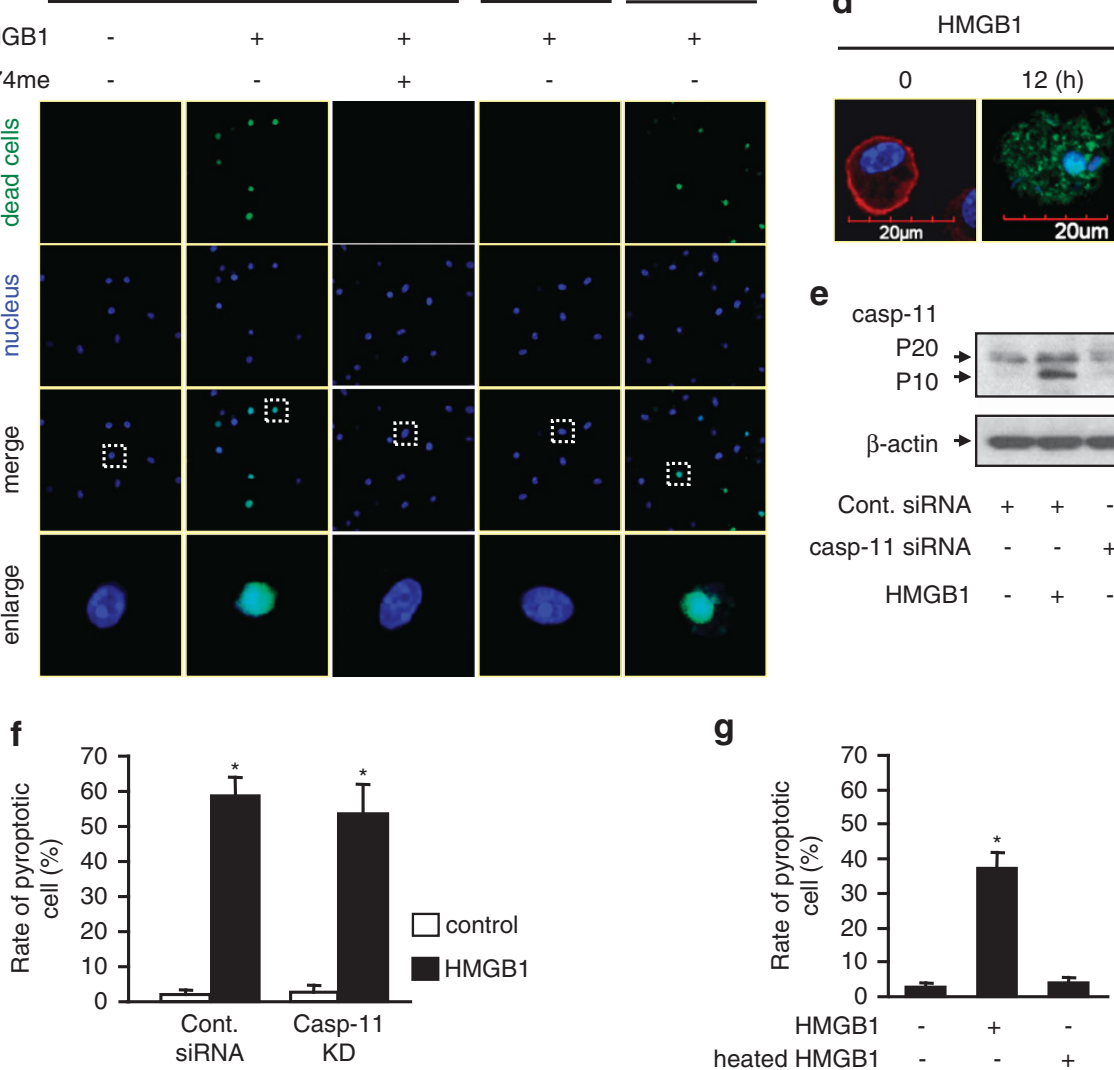

Figure 5 Endocytosis of HMGB1 induces macrophage pyroptosis. (a and $\mathbf{b})$ BMMs were isolated from WT mice (a), caspase-1-deficient (casp-1 ${ }^{-1-}$ ) mice, and NIrp3deficient (NIrp3 ${ }^{-1-}$ ) mice (b), and treated with HMGB1 $(50 \mathrm{nmol} / \mathrm{l})$ for $18 \mathrm{~h}$. In some experiments, Z-YVAD-FMK $(10 \mu \mathrm{mol} / \mathrm{l})$ or CA-074-me $(10 \mu \mathrm{mol} / /)$ was added in the cell cultures (a). At the end of HMGB1 treatment, the BMMs were stained with Cell Death Reagent-TMR and Alexa Fluor 488-labeled caspase-1 FLICA, the double-stained pyroptotic cells were detected by flow cytometry. The rate of pyroptotic cell was calculated by the formula: (pyroptotic cells/total cells) $\times 100 \%$. The graphs show the mean and S.D., $n=3 .{ }^{*} P<0.05$ versus the group labeled with no asterisk. (c) BMMs isolated from WT, caspase- $1^{-1-}$, or Nlrp3 ${ }^{-1-}$ mice were stimulated with HMGB1 for $18 \mathrm{~h}$. In some experiments, CA-074-me was added into the cell culture. The BMMs were then stained with Cell Death Reagent (green) and Hoechst (blue), and fluorescent images were obtained by confocal microscopy (original magnification $\times 600$ ). (d) Confocal microscopy of normal WT BMMs stained with cell mask membrane dye (red) and Hoechst (blue) to show the diameter of macrophage and nucleus (left). WT BMMs were stimulated with HMGB1 for $12 \mathrm{~h}$, and then stained with Hoechst (blue) and FLICA caspase-1 fluorescent reagent (green), which indicates activated caspase-1 (right). Images are representative of three independent experiments (original magnification $\times 600$ ). (e) Mouse macrophage J774.2 cells were transfected with non-specific siRNA (Cont. siRNA) or caspase-11 (Casp-11) siRNA and stimulated with HMGB1 (50 nmol/I) for $12 \mathrm{~h}$. Caspase-11 cleavage (20 and $10 \mathrm{kDa}$ ) in the cell lysates was detected by immunoblotting analysis. (f) J774.2 cells that were transfected with non-specific siRNA (Cont. siRNA) or caspase-11 (Casp-11) siRNA were stimulated with HMGB1 for 18 h. At the end of HMGB1 treatment, the cells were stained with Cell Death Reagent-TMR and Alexa Fluor 488-labeled caspase-1 FLICA, the double-stained pyroptotic cells were detected by flow cytometry. The graphs show the mean and S.D., $n=3 .{ }^{*} P<0.05$ versus the group labeled with no asterisk. (g) WT BMMs were stimulated with HMGB1 $(50 \mathrm{nmol} / \mathrm{L})$ or heated HMGB1 $\left(100^{\circ} \mathrm{C}, 5 \mathrm{~min} ; 50 \mathrm{nmol} / \mathrm{l}\right)$ for $18 \mathrm{~h}$. At the end of $\mathrm{HMGB} 1$ treatment, the cells were stained with Cell Death Reagent-TMR and Alexa Fluor 488-labeled caspase-1 FLICA, the double-stained pyroptotic cells were then detected by flow cytometry. The graphs show the mean and S.D., $n=3 .{ }^{*} P<0.05$ versus the group labeled with no asterisk 


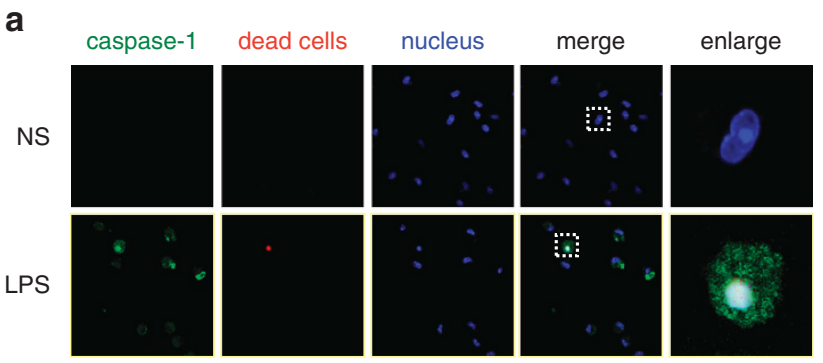

b
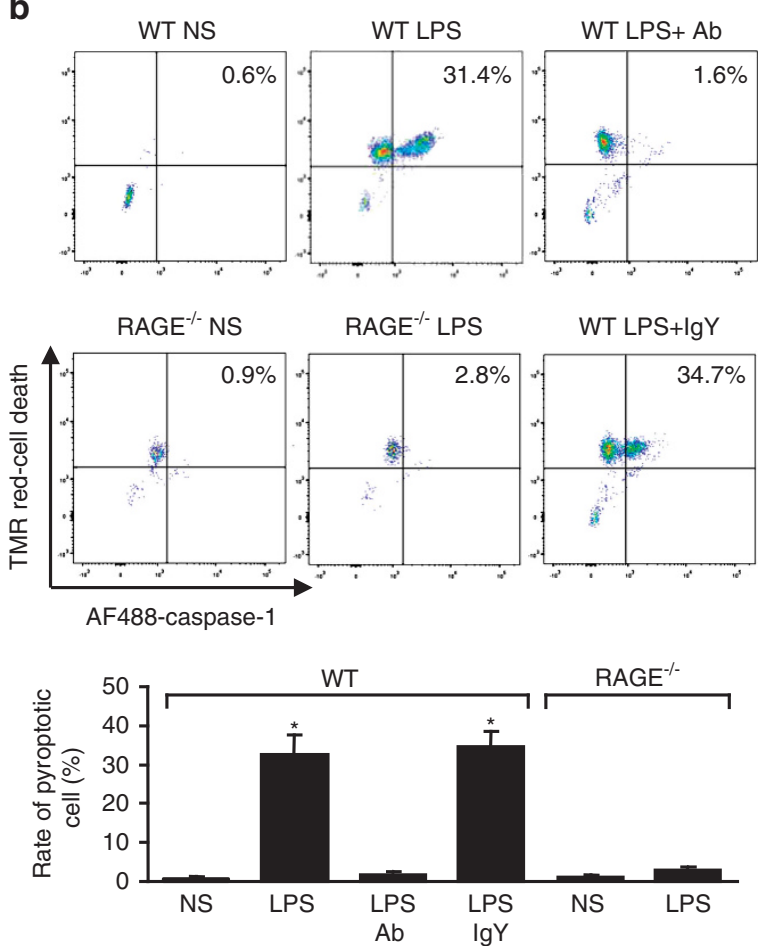

Figure 6 HMGB1 induces macrophage pyroptosis in mouse endotoxemia model. (a) C57BL/6 mice were injected with LPS $(20 \mathrm{mg} / \mathrm{kg} \mathrm{BW}$ ) or normal saline (NS) intraperitoneally (i.p.). AMs were isolated at $18 \mathrm{~h}$ after LPS injection and stained with FLICA caspase-1 fluorescent reagent (green), Cell Death Reagent (red), and Hoechst (blue). Images were obtained by confocal microscopy (original magnification $\times 600$ ). (b) WT or RAGE ${ }^{-1-}$ mice were injected with LPS or NS i.p. Neutralizing anti-HMGB1 IgY (SHINO-TEST Corporation) or control nonimmune lgY (Fitzgerald, North Acton, MA) in a dose of $2 \mathrm{mg} / \mathrm{kg} \mathrm{BW}$ was administered to some animals $30 \mathrm{~min}$ before LPS i.p. injection. Blood monocytes were collected at $18 \mathrm{~h}$ after LPS and stained with Cell Death reagent (TMR red) and FLICA caspase-1 fluorescent reagent (AF488), and double-stained pyroptotic monocytes were detected by flow cytometry. Results are representative of three independent experiments. The graph shows the mean and S.D., $n=3$. ${ }^{*} P<0.05$ versus the group labeled with no asterisk

receptor implicated as a binding partner for HMGB1, the signaling detail of RAGE pathway is largely unknown. ${ }^{32,33}$ Likewise, the linkage between RAGE and dynamin in the pathway is not clear yet and will be a future focus of the study. For many years, endocytosis of ligand molecules has been considered as a mechanism of signal attenuation via receptor and ligand clearance from the cell surface. ${ }^{34,35}$ The current finding that the dynamin-dependent endocytosis of HMGB1 activates a cascade of intracellular events leading to cell pyroptosis, rather than diminishes the effect of HMGB1,

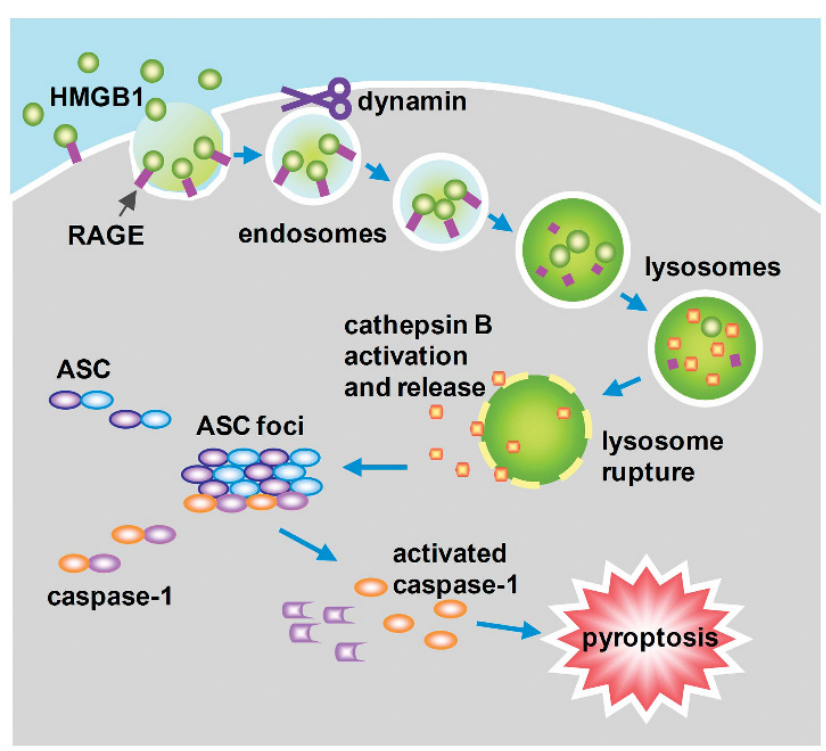

Figure 7 Model of macrophage endocytosis of HMGB1 induces pyroptosis. HMGB1 acting through RAGE on macrophages triggers dynamin-dependent endocytosis of HMGB1, which in turn initiates a cascade of cellular and molecular events. These include CatB activation and release from ruptured lysosome followed by pyroptosome formation and caspase-1 activation, which serves as a mechanism underlying the HMGB1-induced pyroptosis

represents a shift in our understanding of the significance of ligand endocytosis.

Lysosome rupture and lysosomal enzyme CatB release and activation were observed at $6 \mathrm{~h}$ after HMGB1 stimulation of the macrophages. The causal relationship between HMGB1 endocytosis and lysosome destabilization is supported by our data showing that prevention of HMGB1 endocytosis by genetic deletion of RAGE in macrophages, or applying dynamin inhibitor to WT macrophages blocked the induction of lysosome rupture. A recent study has shown that phagocytosis of silica crystal causes lysosome damage and leakage followed by CatB activation. ${ }^{20}$ Although the mechanism of crystal-induced lysosome damage has not been fully elucidated, a physical damaging effect of crystals on the lysosome is plausible. However, lysosome destabilization caused by HMGB1 protein translocating into the lysosome is a first-time observation, and implies a mechanism that involves a RAGE signaling-regulated molecular cascade. Understanding and fully defining this novel HMGB1-signaling pathway are important as this may lead to the identification of a common pathway for the induction of lysosome destabilization.

CatB has been suggested as an upstream activator of NIrp3 inflammasome. ${ }^{20,36}$ In the current study, however, we observed an induction of ASC foci formation, in the absence of Nlrp3 inflammasome activation, following CatB activation. The causal relationship between CatB activation and ASC foci formation is supported by our data that (i) CatB inhibitor suppresses HMGB1-induced ASC foci formation; (ii) HMGB1induced ASC foci were geographically separated within the cell from NIrp3; and (iii) NIrp3 deficiency did not prevent the formation of ASC foci following HMGB1 stimulation. The mechanism by which CatB induces caspase-1-dependent cell pyroptosis is not clear, and will be further studied. 
In this study, two distinct mechanisms of caspase-1 cleavage were identified after HMGB1 stimulation of macrophages. An early detectable caspase-1 cleavage was observed starting at $3 \mathrm{~h}$ after HMGB1 treatment, and this increased over time. The late HMGB1-induced caspase-1 cleavage at $12 \mathrm{~h}$ could be prevented by dynamin inhibition, CatB suppression, or RAGE genetic deletion, but was independent of NIrp3, suggesting a pathway that depends on HMGB1 endocytosis. Whereas, caspase-1 cleavage at $3 \mathrm{~h}$ after HMGB1 treatment was an NIrp3-dependent feature, which is similar to LPS + ATP-induced caspase- 1 cleavage as shown in Figures $3 d$ and e. Collectively, the data suggest that HMGB1 acting through different receptor signaling pathways sequentially induces differential cell responses.

We demonstrate in the current study that suppression of HMGB1 endocytosis or its downstream events, including inhibition of dynamin, CatB, and caspase- 1 activation, prevent pyroptosis in macrophages. These findings support a causal role for HMGB1 endocytosis in induction of cell pyroptosis. Importantly, our in vitro finding was also confirmed in vivo in a model of mouse endotoxemia. The role of HMGB1 in inducing macrophage/monocyte pyroptosis in the endotoxemia model was evident by the fact that neutralizing antibody against HMGB1 significantly decreased monocyte pyroptosis in peripheral blood. Understanding the pathophysiological significance of HMGB1-induced macrophage/monocyte pyroptosis will be our next focus of study.

In summary, our study demonstrates a novel mechanism by which HMGB1 induces macrophage/monocyte pyroptosis through RAGE-mediated HMGB1 endocytosis. The finding sheds light on the regulatory role of ligand-receptor internalization in cell fate, which may have an important role in directing the progress of inflammation following infection and injury.

\section{Materials and Methods \\ Mouse strains. All the mice used in the experiments were 9-10 weeks old and on a C57BL/6 background. WT C57BL/6 mice were purchased from the Jackson Laboratory (Bar Harbor, ME, USA). TLR4 knockout (TLR4 ${ }^{-1-}$ ) mice, TLR2 knockout (TLR2 ${ }^{-1-}$ ) mice, and RAGE knockout (RAGE ${ }^{-1-}$ ) mice were bred in Dr. Billiar's laboratory at the University of Pittsburgh; Caspase-1 knockout (caspase $^{-1} 1^{-1-}$ ) mice were originally provided by Dr. Richard Flavell (Yale University) and Nlrp3 knockout (NIrp3 ${ }^{-1-}$ ) mice were obtained from Millennium Pharmaceuticals (Cambridge, MA, USA). All the animal experimental protocols were reviewed and approved by the Institutional Animal Care and Use Committees of University of Pittsburgh and VA Pittsburgh Healthcare System.}

Endotoxemia mouse model. Mice were given intraperitoneal injection (i.p.) of LPS $(20 \mathrm{mg} / \mathrm{kg}$ BW). Neutralizing anti-HMGB1 $\lg Y$ (SHINO-TEST Corporation, Kanagawa, Japan) or control nonimmune IgY (Fitzgerald, North Acton, MA, USA) in a dose of $2 \mathrm{mg} / \mathrm{kg}$ BW was administered to some animals $30 \mathrm{~min}$ before LPS i.p. At $18 \mathrm{~h}$ after LPS injection, the mice were anesthetized, and then a heart puncture was performed to collect blood samples to measure monocytes pyroptosis using two-color flow cytometry.

Expression vectors and recombinant proteins. The plasmid pGEX4T-HMGB1 is a gift from Dr. Kimitoshi Kohno (University of Occupational and Environmental Health, Japan). His-tagged EGFP prokaryotic expression vector pET14b-His-EGFP was constructed with subcloning sites Kpnl and Xbol by a routine PCR strategy. The coding region of human HMGB1 was amplified by PCR cycles using pGEX-4T-HMGB1 as the template and a pair of specific primers (forward: 5'-CATGGTACCGGCAAAGGAGATCCTAAGAAGC-3'; reverse: 5'-CATG GTACCTTCATCATCATCATCTTCTTCTTCAT-3'). The PCR product was subcloned into $p E T 14 b$-His-EGFP vector. The recombinant plasmids were proved by enzyme digestion and DNA sequencing. The plasmids were transformed into the Escherichia coli strain BL21(DE3, Invitrogen Life Technologies, Carlsbad, CA, USA) followed by induction with $1 \mathrm{mmol} / /$ isopropyl $\beta$-D-thiogalactopyranoside. His-tagged fusion proteins were purified by using Ni-NTA purification system (Invitrogen Life Technologies) and followed by a resolution of 10\% SDS-PAGE. In some experiments, the recombinant proteins HMGB1 and HMGB1-EGFP were heated at $100^{\circ} \mathrm{C}$ for $5 \mathrm{~min}$.

\section{Cell isolation and culture}

BMMs: Mice were euthanized and sprayed with $70 \%$ ethanol. The mouse femurs and tibias were used to prepare BMMs following a standard procedure. ${ }^{37}$ Bone marrow was flushed out with $5 \mathrm{ml} \mathrm{BMM}$ culture medium (DMEM containing $10 \%$ FBS complemented with $50 \mu \mathrm{g} / \mathrm{ml}$ penicillin/streptomycin and $10 \mathrm{ng} / \mathrm{ml}$ recombinant macrophage colony-stimulating factor (Sigma-Aldrich)). BM red blood cells were lysed, and resulting cells were resuspended with BMM culture medium at a concentration of $1 \times 10^{6} \mathrm{cells} / \mathrm{ml}$ and seeded into culture dishes. Fresh BMM medium was added at day 3 and changed once at day 5. BMMs were fully differentiated and ready for use at day 7 .

AMs: AMs were isolated by bronchoalveolar lavage. The lavage fluid was centrifuged at $300 \times g$ at $4{ }^{\circ} \mathrm{C}$ for $10 \mathrm{~min}$, and the pelleted cells were resuspended and cultured in DMEM containing 10\% FBS supplemented with $50 \mu \mathrm{g} / \mathrm{ml}$ penicillin/ streptomycin. After incubation for $2 \mathrm{~h}$, non-adherent cells were washed off with PBS, followed by medium refreshment.

J774.2 mouse macrophage cell line was purchased from Sigma-Aldrich.

Cell staining. Macrophages $\left(5 \times 10^{4}\right.$ cells $)$ were seeded onto a $35-\mathrm{mm}$ Petri dish and grew with DMEM containing $10 \% \mathrm{FBS}$ for $12 \mathrm{~h}$ at $37^{\circ} \mathrm{C}$. After incubation in serum-free DMEM for $30 \mathrm{~min}$, EGFP-tagged HMGB1 (HMGB1-EGFP) was added to the cells with a final concentration of $100 \mathrm{nmol} / \mathrm{l}$. To identify the endocytosis pathways of HMGB1, different fluorophore-conjugated probes were used. Alexa Fluor 594 Transferrin Conjugate $(10 \mu \mathrm{mol} / \mathrm{l}$, Molecular Probes) together with HMGB1-EGFP was incubated with cells for the time as indicated at $37^{\circ} \mathrm{C}$. Lipid Raft Labeling kit (Molecular Probes) was also used to stain cells to identify lipid raft-dependent endocytosis following the manufacturer's instructions. To track the internalized protein in lysosome, LysoTracker Red $(75 \mathrm{nmol} /$; Molecular Probes) was used together with the fluorescent recombinant HMGB1 for up to $24 \mathrm{~h}$ at $37^{\circ} \mathrm{C}$. After incubation for up to $24 \mathrm{~h}$, the cells were washed with PBS, followed by fixation with $4 \%$ paraformaldehyde (Sigma-Aldrich) and nuclear staining with $1 \mu \mathrm{g} / \mathrm{ml} \mathrm{Hoechst} \mathrm{(Sigma-Aldrich)} \mathrm{for} 15 \mathrm{~min}$. The cells were then observed by confocal microscopy (Olympus, Fluoview-FV1000, Olympus America Co., Center Valley, PA, USA).

Detection of lysosome rupture and CatB activation. Macrophages cultured in $35 \mathrm{~mm}$ Petri dishes were treated with HMGB1 $(50 \mathrm{nmol} / \mathrm{l})$ and $\mathrm{DQ}$ Ovalbumin $(10 \mu \mathrm{g} / \mathrm{ml}$, Molecular Probes) or Magic Red CatB assay reagent $\left(10 \mu \mathrm{g} / \mathrm{ml}\right.$, Immunochemistry Technologies, Bloomington, MN, USA) at $37^{\circ} \mathrm{C}$ for $1 \mathrm{~h}$ for detection of lysosome rupture and CatB activity. After fixation with $4 \%$ paraformaldehyde, the cells were visualized by confocal microscopy. Cells were randomly selected for the measurement of intracellular fluorescence intensity by using Olympus FV10-ASW software (Olympus).

Flow cytometry analysis of cell pyroptosis. Two-color flow cytometry was used to detect cell pyroptosis. BMMs, J722.4 cells, or mouse blood monocytes were incubated with Alexa Fluor 488-labeled caspase-1 FLICA at $37^{\circ} \mathrm{C}$ for $1 \mathrm{~h}$. After fixed with $4 \%$ paraformaldehyde, cells were stained with TMR red-labeled In-Situ Cell Death Detection reagent (Roche Applied Science, Indianapolis, IN, USA) following the manufacturer's instructions. The cells were then analyzed by flow cytometry. SSC and FSC were used to differentiate monocytes/macrophages. Background and auto-fluorescence were determined by a control antibody with the same isotype staining. Acquisition was performed on 10000 events using a FACScalibur cytometer (BD Biosciences, San Jose, CA, USA) or BD LSR ॥ (BD Biosciences) and CellQuestPro (BD Biosciences) and FlowJo-V10 software (Tree Star, Ashland, OR, USA). The double-stained cells were counted as pyroptotic cells, and the rate of pyroptotic cell was calculated by the formula: (pyroptotic cells/total cells) $\times 100 \%$.

Western blot. BMM lysates were separated by $12 \%$ SDS-PAGE followed by transferring onto PVDF membranes. After blocking for $1 \mathrm{~h}$ at room temperature 
with blocking buffer (LI-COR Biosciences, Lincoln, NE, USA), blots were incubated with polyclonal antibody against mouse caspase-1 p10 antibody (sc-514, Santa Cruz Biotechnology, Santa Cruz, CA, USA), anti-caspase-11 antibody (ab22648, Abcam, Cambridge, MA, USA), or polyclonal anti-actin antibodies (sc-1615, Santa Cruz Biotechnology). The membranes were washed with PBS for three times and incubated with the appropriate secondary antibodies, respectively (LI-COR Biosciences). Protein bands were detected using Odyssey System from LI-COR Biosciences.

Immunofluorescence confocal microscopy. Macrophages were cytospun onto a microscopic slide and fixed with $4 \%$ paraformaldehyde for 20 min. After washing with PBS, the cells were permeabilized with $0.25 \%$ Triton X-100 in PBS for 10 min at room temperature, followed by blocking with $1 \%$ bovine serum albumin in PBST (PBS with $0.2 \%$ Tween-20) for $2 \mathrm{~h}$ at room temperature to reduce non-specific staining. The cells were then incubated with a primary antibody, including rabbit polyclonal anti-ASC Ab (sc-30153, Santa Cruz Biotechnology) or rabbit polyclonal anti-EEA1 Ab (Cell Signaling Technology, Beverly, MA, USA) at $4{ }^{\circ} \mathrm{C}$ overnight. After washing twice with PBS, the cells were incubated with Alexa Fluor 555-conjugated anti-rabbit IgG (Cell Signaling Technology) for $1 \mathrm{~h}$ at room temperature. Hoechst 33258 (Sigma-Aldrich) was used to stain nuclei. The cells were then washed with PBS for three times, followed by confocal microscopy.

Gene knockdown. J774.2 cells $\left(4 \times 10^{5}\right.$ cells) were cultured in 60 -mm dishes for $24 \mathrm{~h}$ before transfection. $200 \mathrm{pmol}$ per dish mouse ASC siRNA, caspase-11 siRNA, or non-specific siRNA (Santa Cruz Biotechnology) was transfected using Lipofectamine RNAiMAX Transfection Reagent (Invitrogen Life Technologies) following the manufacturer's instructions. At $48 \mathrm{~h}$ after transfection, the efficiency of the corresponding gene knockdown was confirmed with western blot.

Data presentation and statistical analysis. The data are presented as mean \pm S.D. of the indicated number of experiments. SPSS 13.0 (SPSS, Chicago, IL, USA) was used for statistical analysis. Significances between groups were determined by using one-way ANOVA or two-tailed Student's t-test and were considered statistically significant if the $P$ value was less than 0.05 .

\section{Conflict of Interest}

The authors declare no conflict of interest.

Acknowledgements. This work was supported by the National Institutes of Health Grant R01-HL-079669 (JF and MAW), National Institutes of Health Center Grant P50-GM-53789 (TRB and JF), a VA Merit Award (JF), National Key Basic Research Program 2010CB529704 (YJ, China), PCSIRT IRT0731 (YJ), and National Natural Science Foundation of China 30670828 (YJ).

\section{Author Contributions}

JX, JW, XS, QL, YL, ZL, LF planned and did experiments including cell isolation and treatment, confocal microcopy, western blotting, and flow cytometry; JX, JW, XS did animal experiments and histological analysis; YJ, GX, SL, TRB, MAW, and JF planned the project and conceived the experiments; JX, YJ, LF, MJS, and JF conceived the data and wrote the manuscript.

1. Mollen KP, Anand RJ, Tsung A, Prince JM, Levy RM, Billiar TR. Emerging paradigm: Toll-like receptor 4-sentinel for the detection of tissue damage. Shock 2006; 26: 430-437.

2. Martinon F, Petrilli V, Mayor A, Tardivel A, Tschopp J. Gout-associated uric acid crystals activate the NALP3 inflammasome. Nature 2006; 440: 237-241.

3. Wang $\mathrm{H}$, Bloom O, Zhang M, Vishnubhakat JM, Ombrellino M, Che J et al. HMG-1 as a late mediator of endotoxin lethality in mice. Science 1999; 285: 248-251.

4. Lu B, Nakamura T, Inouye K, Li J, Tang Y, Lundback $P$ et al. Novel role of PKR in inflammasome activation and HMGB1 release. Nature 2012; 488: 670-674.

5. Andersson U, Tracey KJ. HMGB1 is a therapeutic target for sterile inflammation and infection. Annu Rev Immunol 2011; 29: 139-162.

6. Wang $H$, Yang H, Czura CJ, Sama AE, Tracey KJ. HMGB1 as a late mediator of lethal systemic inflammation. Am J Respir Crit Care Med 2001; 164(10 Pt 1): 1768-1773.
7. Yang H, Wang H, Czura CJ, Tracey KJ. The cytokine activity of HMGB1. J Leukoc Biol 2005; 78: 1-8.

8. Bucciarelli LG, Wendt T, Rong L, Lalla E, Hofmann MA, Goova MT et al. RAGE is a multiligand receptor of the immunoglobulin superfamily: implications for homeostasis and chronic disease. Cell Mol Life Sci 2002; 59: 1117-1128.

9. van Zoelen MA, van der Sluijs KF, Achouiti A, Florquin S, Braun-Pater JM, Yang $\mathrm{H}$ et al. Receptor for advanced glycation end products is detrimental during influenza A virus pneumonia. Virology 2009; 391: 265-273.

10. van Zoelen MA, Yang $\mathrm{H}$, Florquin S, Meijers JC, Akira S, Arnold B et al. Role of Toll-like receptors 2 and 4 , and the receptor for advanced glycation end products in high-mobility group box 1-induced inflammation in vivo. Shock 2009; 31: 280-284.

11. Hofmann MA, Drury S, Fu C, Qu W, Taguchi A, Lu Y et al. RAGE mediates a novel proinflammatory axis: a central cell surface receptor for $\mathrm{S100/calgranulin} \mathrm{polypeptides.} \mathrm{Cell}$ 1999; 97: 889-901.

12. Huttunen HJ, Kuja-Panula J, Sorci G, Agneletti AL, Donato R, Rauvala H. Coregulation of neurite outgrowth and cell survival by amphoterin and $\mathrm{S} 100$ proteins through receptor for advanced glycation end products (RAGE) activation. J Biol Chem 2000; 275: 40096-40105.

13. Toure F, Zahm JM, Garnotel R, Lambert E, Bonnet N, Schmidt AM et al. Receptor for advanced glycation end-products (RAGE) modulates neutrophil adhesion and migration on glycoxidated extracellular matrix. Biochem $J$ 2008; 416: 255-261.

14. Palumbo R, De Marchis F, Pusterla T, Conti A, Alessio M, Bianchi ME. Src family kinases are necessary for cell migration induced by extracellular HMGB1. J Leukoc Biol 2009; 86: 617-623.

15. Bassi R, Giussani P, Anelli V, Colleoni T, Pedrazzi M, Patrone M et al. HMGB1 as an autocrine stimulus in human T98G glioblastoma cells: role in cell growth and migration. J Neuro-Oncol 2008; 87: 23-33.

16. Kim JY, Park HK, Yoon JS, Kim SJ, Kim ES, Ahn KS et al. Advanced glycation end product (AGE)-induced proliferation of HEL cells via receptor for AGE-related signal pathways. Int J Oncol 2008; 33: 493-501.

17. Hudson BI, Kalea AZ, Del Mar Arriero M, Harja E, Boulanger E, D'Agati V et al. Interaction of the RAGE cytoplasmic domain with diaphanous-1 is required for ligandstimulated cellular migration through activation of Rac1 and Cdc42. J Biol Chem 2008; 283: 34457-34468.

18. Bergsbaken T, Fink SL, Cookson BT. Pyroptosis: host cell death and inflammation. Nat Rev Microbiol 2009; 7: 99-109.

19. Albert ML. Death-defying immunity: do apoptotic cells influence antigen processing and presentation? Nat Rev Immunol 2004; 4: 223-231.

20. Hornung V, Bauernfeind F, Halle A, Samstad EO, Kono H, Rock KL et al. Silica crystals and aluminum salts activate the NALP3 inflammasome through phagosomal destabilization. Nat Immunol 2008; 9: 847-856.

21. Jones LJ, Upson RH, Haugland RP, Panchuk-Voloshina N, Zhou M. Quenched BODIPY dye-labeled casein substrates for the assay of protease activity by direct fluorescence measurement. Anal Biochem 1997; 251: 144-152.

22. Santambrogio L, Sato AK. Carven GJ, Belyanskaya SL, Strominger JL, Stern LJ. Extracellular antigen processing and presentation by immature dendritic cells. Proc Natl Acad Sci USA 1999; 96: 15056-15061.

23. Earnshaw WC, Martins LM, Kaufmann SH. Mammalian caspases: structure, activation, substrates, and functions during apoptosis. Annu Rev Biochem 1999; 68 383-424.

24. Xiang M, Shi X, Li Y, Xu J, Yin L, Xiao G et al. Hemorrhagic shock activation of NLRP3 inflammasome in lung endothelial cells. J Immunol 2011; 187: 4809-4817.

25. Xu P, Wen Z, Shi X, Li Y, Fan L, Xiang M et al. Hemorrhagic shock augments Nlrp3 inflammasome activation in the lung through impaired pyrin induction. J Immunol 2013; 190: 5247-5255.

26. Stehlik C, Lee SH, Dorfleutner A, Stassinopoulos A, Sagara J, Reed JC. Apoptosisassociated speck-like protein containing a caspase recruitment domain is a regulator of procaspase-1 activation. J Immunol 2003; 171: 6154-6163.

27. Miao EA, Rajan JV, Aderem A. Caspase-1-induced pyroptotic cell death. Immunol Rev 2011; 243: 206-214

28. Hansen CG, Nichols BJ. Molecular mechanisms of clathrin-independent endocytosis J Cell Sci 2009; 122(Pt 11): 1713-1721.

29. Bashkirov PV, Akimov SA, Evseev Al, Schmid SL, Zimmerberg J, Frolov VA. GTPase cycle of dynamin is coupled to membrane squeeze and release, leading to spontaneous fission. Cell 2008; 135: 1276-1286.

30. Pucadyil TJ, Schmid SL. Real-time visualization of dynamin-catalyzed membrane fission and vesicle release. Cell 2008; 135: 1263-1275.

31. Roux A, Antonny B. The long and short of membrane fission. Cell 2008; 135: 1163-1165.

32. Hori O, Brett J, Slattery T, Cao R, Zhang J, Chen JX et al. The receptor for advanced glycation end products (RAGE) is a cellular binding site for amphoterin. Mediation of neurite outgrowth and co-expression of rage and amphoterin in the developing nervous system. J Biol Chem 1995; 270: 25752-25761. 
33. Schmidt AM, Hori O, Chen JX, Li JF, Crandall J, Zhang J et al. Advanced glycation endproducts interacting with their endothelial receptor induce expression of vascular cell adhesion molecule-1 (VCAM-1) in cultured human endothelial cells and in mice. A potential mechanism for the accelerated vasculopathy of diabetes. J Clin Invest 1995; 96: 1395-1403.

34. Di Guglielmo GM, Le Roy C, Goodfellow AF, Wrana JL. Distinct endocytic pathways regulate TGF-beta receptor signalling and turnover. NatCcell Biol 2003; 5: 410-421.
35. Sigismund S, Argenzio E, Tosoni D, Cavallaro E, Polo S, Di Fiore PP. Clathrin-mediated internalization is essential for sustained EGFR signaling but dispensable for degradation. Dev Cell 2008; 15: 209-219.

36. Zitvogel L, Kepp O, Kroemer G. Decoding cell death signals in inflammation and immunity. Cell 2010; 140: 798-804.

37. Weischenfeldt J, Porse B. Bone marrow-derived macrophages (BMM): isolation and applications. CSH Protoc 2008; 2008: pdb prot5080. 